www.jcmtjournal.com

\title{
Insights into mechanisms of tumor dissemination from circulating tumor cell lines of small cell lung cancer
}

\author{
Gerhard Hamilton, Barbara Rath \\ Society for Research on Biology and Treatment of Cancer, A-1160 Vienna, Austria. \\ Correspondence to: Dr. Gerhard Hamilton, Society for Research on Biology and Treatment of Cancer, A-1160 Vienna, Austria. \\ E-mail: hamilton.srbtc@gmx.org; gerhard.hamilton@meduniwien.ac.at
}

How to cite this article: Hamilton G, Rath B. Insights into mechanisms of tumor dissemination from circulating tumor cell lines of small cell lung cancer. J Cancer Metastasis Treat 2016;2:446-52.

\begin{tabular}{l} 
Article history: \\
Received: $21-09-2016$ \\
Accepted: $01-12-2016$ \\
Published: $16-12-2016$ \\
\hline Key words: \\
Cancer metastasis, \\
small cell lung cancer, \\
circulating tumor cells, \\
epithelial-mesenchymal transition, \\
tumorosphere, \\
chemotherapy, \\
drug resistance
\end{tabular}

\begin{abstract}
Despite the fact that the majority of cancer patients succumb to metastatic disease, most aspects of tumor metastasis are not understood in detail at present. Cell biologic steps of dissemination are difficult to characterize in human tumors and research is in large part confined to cell line and experimental animal studies. Epithelial-mesenchymal transition (EMT), intravasation of malignant cells, dissemination as circulating tumor cells (CTCs) and eventually mesenchymal-epithelial transition (MET) at distal sites are steps believed to be involved in metastasis. Small cell lung cancer (SCLC) is distinguished by early dissemination and excessive numbers of CTCs, which allowed for the ex vivo expansion of six permanent CTC lines taken from relapsed patients. Cells exhibit an epithelial phenotype with partial EMT traits and are chemoresistant due to formation of large tumorospheres. Since cells may have invaded without undergoing EMT, the role of MET is uncertain. These SCLC CTC cell lines seem to represent the metastasis-inducing cancer cells; these are the minute subpopulation of CTCs capable of surviving in the circulation and transitioning to metastases, leading in turn to resistance and failure of therapy. Full characterization of these lines is expected to provide the markers to find the relevant CTCs among the highly heterogeneous population observable in the context of tumor recurrence.
\end{abstract}

\section{INTRODUCTION}

Early detection, precise diagnosis and monitoring of the course of disease during therapy are the objective of individualized care in current oncology. For most tumors, a tumor biopsy is costly, painful, or potentially hazardous for the patient and is not performed during the further development of the malignancy. Especially in tumor types showing a high frequency of systemic disease, such as small cell lung cancer (SCLC), a small needle biopsy is procured first to confirm the diagnosis, and chemotherapy is started without any further invasive procedure. ${ }^{[1]}$ Thus, the opportunity to obtain essential information from blood samples, as so-called

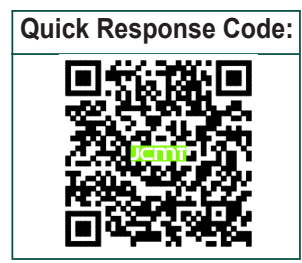


liquid biopsies, would offer significant advantages.Noninvasive detection and monitoring of patient tumors, employing cell-free circulating tumor DNA (ctDNA) or circulating tumor cells (CTCs), have been employed for investigations into multiple tumor types. ${ }^{[2-4]}$ CTCs are described as cells, shed by primary or secondary tumors into vasculature, that keep circulating in the bloodstream of cancer patients ${ }^{[5]}$ Reports indicate that patients with lower counts of CTCs survive longer than the patients with higher CTCs counts. For example, lower numbers of CTCs were observed for 21 patients with limited SCLC (median $=6$, range 0-220) compared with 38 patients with extensive stage (median $=63$, range $0-14,040$ ) and the absence of measurable CTCs in $27 \%$ of patients was correlated with prolonged survival (hazard ratio: $3.4 ; P \leq 0.001)^{[6]}$

Furthermore, CTC counts have been proposed as a surrogate marker for assessment of responses to therapy in cancer patients to facilitate more rapid drug evaluation. The Food and Drug Administration approved CellSearch ${ }^{\odot}$ system (Veridex, Raritan, NJ, USA) enumerates intact CTCs for a prognosis of overall survival for breast, prostate and colon cancer. ${ }^{[7]}$ For example, CTC count is a robust independent prognostic factor for progression-free recovery and overall survival in patients with early and metastatic breast cancer ${ }^{\left[{ }^{[8]}\right.}$ Additionally, CTCs have been detected in patients with chronic obstructive pulmonary disease before the actual occurrence of malign lesions, thus allowing for early diagnosis of lung cancer. ${ }^{\left[{ }^{[9]}\right.}$ However, an advantage of the analysis of ctDNA in liquid biopsy is the detection of molecular changes which are occurring within the tumors in real time, especially during development of drug resistance to targeted agents. ${ }^{[2,3]}$ Numerous techniques for the enrichment of CTCs have been developed relying on immunological markers, size, rigidity or dielectric properties. These techniques have been used for genetic characterization, marker analysis and short-term cultures for investigation of their cell biology. ${ }^{[10,11]}$ Despite a host of studies dealing with CTCs, many questions regarding their generation, shedding, survival in the circulation, chemosensitivity and mechanisms of induction of secondary lesion remain to be fully resolved.

Research on tumor dissemination and CTCs has been hampered by the scarcity or heterogeneity of the enriched cells, as well as the inability to define the characteristics of the actual metastasis-inducing CTCs that are expected to be most relevant for the prognosis of the patients. In this study, we have established for the first time six CTC cell lines from a variety of patients with extended metastatic SCLC and present here the implications of the phenotype of these cell lines for tumor dissemination in this highly aggressive malignancy.

\section{DETECTION AND ENRICHMENT OF CTCS}

In most tumor types, CTCs are rare events, with a frequency of approximately one CTC among 1-10 million mononuclear blood cells. Therefore, these cancer cells have to be enriched by various methods for further analysis. The probability to detect CTCs in a limited volume of blood has been reviewed by Gkountela et al. ${ }^{[10]}$ and the reported probability of collecting $\geq 1$ CTCs in one aliquot of $7.5 \mathrm{~mL}$ blood from a patient with 500 CTCs is $50 \%$. Therefore, $20 \mathrm{~mL}$ of whole blood would have to be assessed if the cell event were to be detected for a lower frequency at one CTC in $10^{7}$ leukocytes. The frequency of the CTC population measured in an aliquot may not be a statistical representative of the entire sample.

There are a number of questions remaining for the detection of CTCs and their relationship to their parent bulk tumors. CTCs seem to stem from the frontier of the tumor and it is generally known that the tumor margin is different from the main tumor mass. Most of the CTCs populations analyzed exhibit heterogeneity, pointing to release of different cell populations from distinct regions of the tumor or of metastatic lesions. ${ }^{[11]}$ CTCs can also form clusters including immune cells in the circulation, or be engulfed by the platelets before eventually adhering to the walls of the capillaries and initiating extravasation. ${ }^{[12]}$

The role of CTCs as prognostic marker and as possible surrogate indicators for response to therapy is discussed in numerous reviews. ${ }^{[10,13,14]}$ CTCs which are shed from tumors are mediators of metastatic dissemination and form micrometastasis at distant organs. ${ }^{[15]}$ In positive selection, surface markers of CTCs are targeted, whereas, in negative selection, depletion of blood cells other than CTCs is achieved by targeting their surface markers. ${ }^{[10]}$ The CellSearch ${ }^{\circledR}$ system is by far the most common system for extraction and enumeration of CTCs for clinical investigations. ${ }^{[7]}$ CTCs which have downregulated EpCAM remain undetected throughout this process. ${ }^{[16,17]}$ By alternative methods, cell size-based sorting is accomplished using microfluidic technology, as with the Parsortix system (Angle, Guildford, UK). ${ }^{[18,19]}$ Isolation by Size of Tumor cells (ISET ${ }^{\circledR}$ ) is a another filter-based established method which is used for such cell sizebased sorting. ${ }^{[20]}$

CTCs derived from breast cancer patients are among the most extensively studied for diagnosis 
and treatment.[21] The presence of CTCs, despite ongoing treatment, has proven to be an indicator of worse overall survival; therefore, in one group of HER2 breast cancer patients, HER2 ${ }^{+}$CTCs were identified and trastuzumab-based therapy applied to these patients. ${ }^{[17,22,23]}$ Most of the CTCs isolated from breast cancer patients show the presence of epithelialmesenchymal transition (EMT) markers such as ETV5, NOTCH1, SNAIL, TGFB1, ZEB1, and ZEB2. ${ }^{[24]}$ Breast cancer patients who showed remaining CTCs after first cycles of chemotherapy progressed rapidly to metastatic disease. ${ }^{[25]}$ In prostate cancer, CTCs have been proposed to act as intermediate or surrogate endpoints for survival and to shorten timelines for drug approval. ${ }^{[26]}$ Patients with lower levels of CTCs have shown slower disease progression in comparison to those having higher levels of CTCs. ${ }^{[27]}$ In colon cancer, CTCs were found as individual cells or as clusters (CTMs) by a CK-based, immunomagnetic cell separation method. ${ }^{[28]}$ CTMs are of particular interest as they are considered to be markers of increased metastatic potential. ${ }^{[29]}$ In lung cancer, CellSearch ${ }^{\circledR}$ and ISET kits indicated a higher number of CTCs in SCLC than NSCLC, reported to be associated with larger tumor size and bone metastasis. ${ }^{[30,31]}$ The high numbers of CTCs in SCLC allowed for their enrichment and initiation of xenografts which seem to resemble the tumor characteristics of the respective patients. ${ }^{[32]}$ Furthermore, a trial to establish ex vivo expanded CTC cell lines was successful and has resulted in the availability of six lines from relapsed patients so far. ${ }^{[33]}$ Characteristics of the first CTC cell lines and their interaction with macrophages have been published. ${ }^{[34]}$

\section{SHEDDING OF CTCS FROM TUMORS}

Release of CTCs into the circulation is frequently termed shedding, a designation for a process for which the details are not known. CTCs are reported to be shed from solid tumors at a daily rate of 3.2 to $4.1 \times 10^{6}$ per gram of tissue, based on a single artificial rat model..[35] In one study, the rate of tumor cell shedding into efferent blood was measured in both growing and regressing MTW9 rat mammary carcinomas. Cell shedding rates of growing versus regressing tumors were not significantly different over a tumor size range of 2-4 g. Half of these CTCs perished within $2.4 \mathrm{~h}$, although longer half-lives were reported in a clinical setting. ${ }^{[28,36]}$ Tumor cells are rapidly cleared from circulating blood and a 2-g MTW9 carcinoma reportedly released enough cells into the circulation to transplant the tumor every $24 \mathrm{~h}$, although the majority of the cells were reported to be apoptotic/ necrotic. ${ }^{[35]}$ The cell loss via blood comprised about $10 \%$ of the tumor weight and resulted in a CTC count of approximately 20,000 CTCs $/ \mathrm{mL}$ blood.

Clearly, this estimation of the release of CTCs reported from an experimental animal model cannot be extrapolated to human tumors. No form of the shedding of CTCs causes a human tumor to lose $10 \%$ of its size in one day, nor is a CTC count of 20,000 cells $/ \mathrm{mL}$ observed in most cancer patients. A threshold of $5 \mathrm{CTCs} / 7.5 \mathrm{~mL}$ blood has been defined by the Cellsearch ${ }^{\odot}$ system for breast and prostate cancer, and a lower threshold of 3 CTCs $/ 7.5 \mathrm{~mL}$ blood has been defined for colon cancer patients. These figures are for favorable or poor prognosis, respectively. ${ }^{[7,37]}$ Consequently, the attrition rate in the circulation based on this artificial animal model seems to be a considerable overestimation. The specific mechanisms of tumor cell shedding are not known at present. CTCs seem to origin as specialized cell types, different from the bulk of the tumor cells, from the borders of the tumor. CTCs leave the particular microenvironmental milieu characterized by inflammation, acidosis and hypoxia through the interaction of a host of participating cell types. Therefore, CTCs are not expected to represent the bulk of tumor cells and are not typical of the cell biologic behavior and chemoresistance of the main body of the tumor. SCLC extended disease responds well to the first cycles of platinum-based chemotherapy but recurs within approximately one year as tumors which exhibit universal chemoradioresistance. ${ }^{[38]}$ Contrary to expectations, the first two SCLC CTC cell lines proved to be chemosensitive to the secondline chemotherapeutics topotecan and epirubicin although some tumor cells must have survived the initial successful treatment and eventually give rise to chemoresistant relapses. ${ }^{[39]}$ Therefore, the use of CTCs as surrogate markers for the bulk tumor is questionable.

\section{EMT IN TUMOR CELL SHEDDING}

A general assumption supposes that tumor cells invade through a process termed EMT. ${ }^{[40]}$ Accordingly, epithelial tumor cell downregulate epithelial markers, such as E-cadherin, EpCAM and cytokeratins, eventually expressing mesenchymal markers such as vimentin, neural cell adhesion molecule (NCAM) and others. In this way, cells gain mobility and migrate to intravasate and reach distant sites to establish secondary lesions. EMT is regulated by a number of specific transcription factors belonging to the SNAIL, TWIST and ZEB families und is modulated by microenvironmental conditions, inflammatory cytokines and chemotherapy. ${ }^{[41]}$ Since it has proven difficult to demonstrate tumor cells with EMT traits in patients, incomplete EMT or transitional EMT has been proposed as a model. This model 
presupposes no complete switch in phenotype, but rather a type of transition which may be as minimal as a slight downregulation of epithelial features. EMT phenotypes have been reported among heterogeneous CTC populations and increased fractions of cells with such mesenchymal features have been demonstrated to correlate with a poorer prognosis in breast cancer patients. ${ }^{[24]}$

It may still be possible that tumor cells with epithelial characteristics enter the bloodstream without undergoing EMT. An alternative model, termed "cooperative migration", posits that EMT-type cells help epithelial cells to gain access to the circulation, but to reside at the bulk tumor. Excessive numbers of CTCs have been observed in SCLC, which is frequently associated with local inflammation and in inflammatory breast cancer. Thus, immune cells and inflammation may promote release of tumor cells into the circulation possibly without EMT. The SCLC CTC cell lines have been found to recruit macrophages and to lack a phenotypic switch with full expression of mesenchymal traits. ${ }^{[34,42]}$ In conclusion, complete or partial EMT is not proven to be a prerequisite to disseminate tumor cells, and therapeutic options to inhibit such a transition need to be considered cautiously. ${ }^{[43]}$

\section{SURVIVAL CTCS IN THE CIRCULATION}

The great majority of CTCs seem to be short-lived and to perish in the circulation. Of the several forms of CTCs shed by the primary tumor, only about $0.1 \%$ survive in the circulation and only about $0.01 \%$ is responsible for metastasis. ${ }^{[8,10]}$ This attrition has been attributed to shear stress and an unfavorable microenvironment too different from the local tumor conditions. CTCs in the hematogenous circulation must survive a variety of stresses, and epithelial cells may undergo anoikis in the absence of cellular attachment. ${ }^{[44]}$ The vast majority of CTCs are likely to become trapped in various capillary beds. They are destroyed by hemodynamic shear forces and predation by cells of the innate immune system - specifically natural killer cells. Consistent with this view, a great deal of CTC-associated material is detectable in CTC-positive tumor patients. ${ }^{[10]}$ Reported half-lives have ranged from several hours, according to experimental animal models, to long-term persistence. The SCLC CTC lines show continuing disposal of microparticles and cellular fragments, thus generating CTC associated materials under optimal conditions in tissue culture in the absence of shear stress. ${ }^{[42]}$ Partial disintegration of CTC tumorospheres may function as a source of decoy material to protect other CTCs and the bulk tumor from attacks by both the immune system and chemotherapeutics.

\section{INDUCTION OF EXTRAVASATION AND MESENCHYMAL-EPITHELIAL TRANSITION}

In general, the secondary lesions induced by CTCs show an epithelial phenotype similar to the originating primary tumor. ${ }^{[40]}$ Provided that the metastases were established by cells which underwent EMT, at some point during tumor spread and extravasation this transition has to be reversed through a process termed mesenchymal-epithelial transition (MET). This process has not been observed directly, but has been inferred from the mesenchymal traits of disseminated/ CTCs and the histology of secondary lesions. ${ }^{[45]}$ The factors causing this supposedly phenotypic switch, along with their possible derivation from the cancer cells themselves (seed) or the metastatic site (soil) are largely unknown. In the case of SCLC CTC lines, the cells are positive for EpCAM, E-cadherin and proteins involved in cell junctions and form spontaneously typical large spheroids with diameters of up to 1-2 mm in regular tissue culture medium without any factors preventing adhesion to cell culture flasks. ${ }^{[43]}$ Although expression of vimentin and NCAM is observed, the formation of these organized and large spheres is a typical epithelial feature not observed in SCLC tumor cell lines in vitro. Since these tumorospheres develop from CTCs of relapsed SCLC patients within a short time, and are found in cell suspension derived from xenografts induced by such CTCs, they seem not to stem from an in vitro transition in tissue culture but to present the original in vivo phenotype. Thus, these metastasis-inducing CTCs seem to be present as cancer cells exhibiting an epithelial phenotype and organization and may be trapped in capillaries or reside in protected sites, possibly in a dormant state. Tumorospheres exceeding diameters of $2 \mathrm{~mm}$ during their development tend to disintegrate and may be the source of non-proliferating cell clusters observed in the blood of metastatic cancer patients. ${ }^{[10]}$

\section{METASTASIS AND DRUG RESISTANCE}

Metastases not only damage secondary organs and exacerbate the deleterious effects of malignancies in general but frequently exhibit chemoresistance to reinitiation of primary or second-line chemotherapy agents. Especially in SCLC, excellent response rates to initial chemotherapy can be followed by relapses within approximately one year, which exhibit broad chemoresistance and result in failure of treatment. ${ }^{[1,38]}$

Attempts have been made to characterize the chemosensitivity of CTCs in short term cultures in various tumorentities. ${ }^{[46]}$ However, CTCs are specialized cells different from the tumor bulk and most likely also 
from the developing metastases. It was universally assumed that CTCs survive as chemoresistant cells and may predict the responsiveness of resulting secondary lesions. Surprisingly, the SCLC CTC lines were found to be highly chemosensitive to agents of common use in this tumor entity, except the CTC line established from a patient refractory to initial therapy with cisplatin. ${ }^{[39]}$ Thus, some tumor cells have survived the initial cycles of chemotherapy, possibly in an inflammatory environment, and seem to develop a kind of chemoresistance not accomplished at the cellular level. ${ }^{[34]}$ Tumorospheres are known to be comprised of a small region of proliferating cells and layers of quiescent cells surrounding an inner hypoxic core which provides protection against irradiation due to the lack of reactive oxygen species [Figure 1]. ${ }^{[47,48]}$

Therapy of SCLC has not been improved for the last several decades despite the clinical testing of a host of chemotherapeutics covering the widest range of clinical targets available..$^{[1,49]}$ More than 600 trials exploring therapeutic interventions in SCLC are currently in the U.S. clinical trials registry, National Institutes of Health. ${ }^{[50]}$ Since it is not reasonable to assume that SCLC tumors express a host of individual molecular mechanisms, tumorospheres provide an alternative explanation for chemoresistance, in which potential chemotherapeutic drugs are prevented from reaching their cellular target (in responsive cells) in sufficient quantities. ${ }^{[51]}$ Whether the validity of this kind of chemoresistance, in the form of tumor spheroids, is

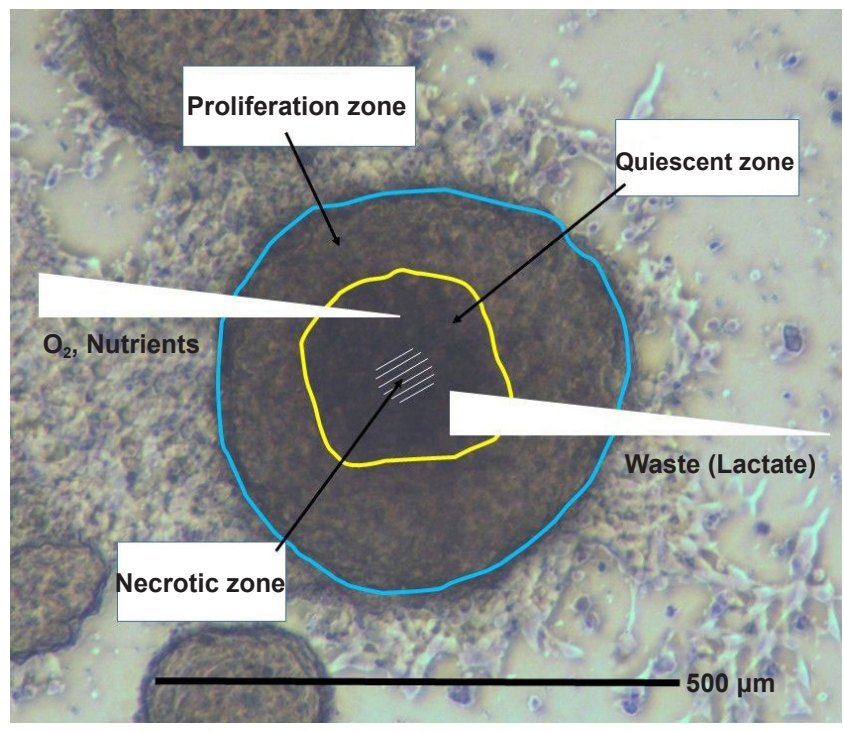

Figure 1: Cell physiologic conditions in an SCLC CTC tumorosphere. This figure shows a microscopic image of a SCLC CTC BHGc10 tumorosphere with a schematic overlay indicating regions of proliferating, quiescent and hypoxic cells. These spheroid structures grow up to diameters of 1-2 millimeters and develop gradients of nutrient and oxygen supply as well as accumulation of metabolic waste products. SCLC: small cell lung cancer; CTC: circulating tumor cell confined to SCLC or is common to other tumor types, remains to be investigated.

\section{CONCLUSION}

Mechanisms of tumor metastasis have been investigated using numerous cell culture studies and research employing experimental animal models as well as analyses of clinical specimens. Models have been proposed for the discrete steps of tumor metastasis, but the actual dissemination of malignancies in patients is difficult to assess. Clearly, CTCs are instrumental in translocation of tumor cells to distal sites and in the induction of secondary lesions. Although CTC counts have shown prognostic significance, their limited accessibility and marked heterogeneity have limited their usefulness.

A panel of permanent CTC lines from SCLC patients revealed absence of full EMT, presence of chemosensitivity, and an epithelial phenotype with formation of tumorospheres as physical barrier against chemoradiotherapy. Unfortunately, there are currently no means available to target these spheroid structures in a clinical setting, and further investigation is needed to study the cell biology of CTC aggregates in detail, and to study overcoming resistance using targeted agents involving enzymes, cell junctions opener, nanomaterials and other mechanisms.

\section{Acknowledgments}

The authors wish to thank all clinical and laboratory staff involved in the project of generating CTC cell lines of SCLC patients and Dr. B. T. Hohenheim for endorsement.

\section{Financial support and sponsorship} Nil.

\section{Conflicts of interest}

There are no conflicts of interest.

\section{Patient consent}

Informed patient consent was obtained throughout the study.

\section{Ethics approval}

The respective ethics protocol (Approval of the Medical University of Vienna Nr. 366/2003 and amendments obtained prior to the commencement of the study) was followed throughout the study.

\section{REFERENCES}

1. Pietanza MC, Byers LA, Minna JD, Rudin CM. Small cell lung cancer: will recent progress lead to improved outcomes? Clin Cancer 
Res 2015;21:2244-55.

2. Karachaliou N, Mayo-de-Las-Casas C, Molina-Vila MA, Rosell R. Real-time liquid biopsies become a reality in cancer treatment. Ann Transl Med 2015;3:36.

3. Rolfo C, Castiglia M, Hong D, Alessandro R, Mertens I, Baggerman G, Zwaenepoel K, Gil-Bazo I, Passiglia F, Carreca AP, Taverna S, Vento R, Santini D, Peeters M, Russo A, Pauwels P. Liquid biopsies in lung cancer: the new ambrosia of researchers. Biochim Biophys Acta 2014;1846:539-46.

4. Potdar PD, Lotey NK. Role of circulating tumor cells in future diagnosis and therapy of cancer. $J$ Cancer Metastasis Treat 2015;1:44-56.

5. Yap TA, Lorente D, Omlin A, Olmos D, de Bono JS. Circulating tumour cells: a multifunctional biomarker. Clin Cancer Res 2014;20:2553-68.

6. Hiltermann TJ, Pore MM, van den Berg A, Timens W, Boezen HM, Liesker JJ, Schouwink JH, Wijnands WJ, Kerner GS, Kruyt FA, Tissing H, Tibbe AG, Terstappen LW, Groen HJ. Circulating tumor cells in small-cell lung cancer: a predictive and prognostic factor. Ann Oncol 2012;23:2937-42.

7. Andree KC, van Dalum G, Terstappen LW. Challenges in circulating tumor cell detection by the CellSearch system. Mol Oncol 2016;10:395-407.

8. Paoletti C, Hayes DF. Circulating tumor cells. Adv Exp Med Biol 2016;882:235-58.

9. Ilie M, Hofman V, Long-Mira E, Selva E, Vignaud JM, Padovani B, Mouroux J, Marquette CH, Hofman P. "Sentinel" circulating tumor cells allow early diagnosis of lung cancer in patients with chronic obstructive pulmonary disease. PLoS One 2014;9:e111597.

10. Gkountela S, Szczerba B, Donato C, Aceto N. Recent advances in the biology of human circulating tumour cells and metastasis. ESMO Open 2016;1:e000078.

11. Ferreira MM, Ramani VC, Jeffrey SS. Circulating tumor cell technologies. Mol Oncol 2016;10:374-94.

12. Leblanc R, Peyruchaud O. Metastasis: new functional implications of platelets and megakaryocytes. Blood 2016;128:24-31.

13. Krebs MG, Metcalf RL, Carter L, Brady G, Blackhall FH, Dive C. Molecular analysis of circulating tumour cells-biology and biomarkers. Nat Rev Clin Oncol 2014;11:129-44.

14. Alix-Panabières C, Pantel K. Clinical applications of circulating tumor cells and circulating tumor DNA as liquid biopsy. Cancer Discov 2016;6:479-91.

15. Bidard FC, Peeters DJ, Fehm T, Nolé F, Gisbert-Criado R, Mavroudis D, Grisanti S, Generali D, Garcia-Saenz JA, Stebbing J, Caldas C, Gazzaniga P, Manso L, Zamarchi R, de Lascoiti AF, De Mattos-Arruda L, Ignatiadis M, Lebofsky R, van Laere SJ, Meier-Stiegen F, Sandri MT, Vidal-Martinez J, Politaki E, Consoli F, Bottini A, Diaz-Rubio E, Krell J, Dawson SJ, Raimondi C, Rutten A, Janni W, Munzone E, Carañana V, Agelaki S, Almici C, Dirix L, Solomayer EF, Zorzino L, Johannes H, Reis-Filho JS, Pantel K, Pierga JY, Michiels S. Clinical validity of circulating tumour cells in patients with metastatic breast cancer: a pooled analysis of individual patient data. Lancet Oncol 2014; $15: 406-14$

16. Sun YF, Yang XR, Zhou J, Qiu SJ, Fan J, Xu Y. Circulating tumor cells: advances in detection methods, biological issues, and clinical relevance. J Cancer Res Clin Oncol 2011;137:1151-73.

17. Polzer B, Medoro G, Pasch S, Fontana F, Zorzino L, Pestka A, Andergassen U, Meier-Stiegen F, Czyz ZT, Alberter B, Treitschke S, Schamberger T, Sergio M, Bregola G, Doffini A, Gianni S, Calanca A, Signorini G, Bolognesi C, Hartmann A, Fasching PA, Sandri MT, Rack B, FehmT, Giorgini G, Manaresi N, Klein CA. Molecular profiling of single circulating tumor cells with diagnostic intention. EMBO Mol Med 2014;6:1371-86.

18. Karabacak NM, Spuhler PS, Fachin F, Lim EJ, Pai V, Ozkumur E, Martel JM, Kojic N, Smith K, Chen PI, Yang J, Hwang H, Morgan
B, Trautwein J, Barber TA, Stott SL, Maheswaran S, Kapur R, Haber DA, Toner M. Microfluidic, marker-free isolation of circulating tumour cells from blood samples. Nat Protoc 2014;9:694-710.

19. Xu L, Mao X, Imrali A, Syed F, Mutsvangwa K, Berney D, Cathcart P, Hines J, Shamash J, Lu YJ. Optimization and evaluation of a novel size based circulating tumor cell isolation system. PLoS One 2015; 10:e0138032.

20. Vona G, Sabile A, Louha M, Sitruk V, Romana S, Schütze K, Capron F, Franco D, Pazzagli M, Vekemans M, Lacour B, Bréchot C, Paterlini-Bréchot P. Isolation by size of epithelial tumor cells: a new method for the immunomorphological and molecular characterization of circulating tumor cells. Am J Pathol 2000;156:57-63.

21. Aceto N, Bardia A, Miyamoto DT, Donaldson MC, Wittner BS, Spencer JA, Yu M, Pely A, Engstrom A, Zhu H, Brannigan BW, Kapur R, Stott SL, Shioda T, Ramaswamy S, Ting DT, Lin CP, Toner M, Haber DA, Maheswaran S. Circulating tumour cell clusters are oligoclonal precursors of breast cancer metastasis. Cell 2014;158:1110-22.

22. Riethdorf S, Müller V, Zhang L, Rau T, Loibl S, Komor M, Roller M, Huober J, Fehm T, Schrader I, Hilfrich J, Holms F, Tesch H, Eidtmann H, Untch M, von Minckwitz G, Pantel K. Detection and HER2 expression of circulating tumour cells: prospective monitoring in breast cancer patients treated in the neoadjuvant GeparQuattro trial. Clin Cancer Res 2010;16:2634-45.

23. Krishnamurthy S, Bischoff F, Ann Mayer J, Wong K, Pham T, Kuerer H, Lodhi A, Bhattacharyya A, Hall C, Lucci A. Discordance in HER2 gene amplification in circulating and disseminated tumor cells in patients with operable breast cancer. Cancer Med 2013;2:226-33.

24. Krawczyk N, Meier-Stiegen F, Banys M, Neubauer H, Ruckhaeberle E, Fehm T. Expression of stem cell and epithelial-mesenchymal transition markers in circulating tumor cells of breast cancer patients. Biomed Res Int 2014;2014:415721.

25. Smerage JB, Barlow WE, Hortobagyi GN, Winer EP, Leyland-Jones B, Srkalovic G, Tejwani S, Schott AF, O'Rourke MA, Lew DL, Doyle GV, Gralow JR, Livingston RB, Hayes DF. Circulating tumor cells and response to chemotherapy in metastatic breast cancer: SWOG S0500. J Clin Oncol 2014;32:3483-9.

26. de Bono JS, Scher HI, Montgomery RB, Parker C, Miller MC, Tissing H, Doyle GV, Terstappen LW, Pienta KJ, Raghavan D. Circulating tumor cells predict survival benefit from treatment in metastatic castration-resistant prostate cancer. Clin Cancer Res 2008;14:6302-9.

27. Moreno JG, Miller MC, Gross S, Allard WJ, Gomella LG, Terstappen LW. Circulating tumor cells predict survival in patients with metastatic prostate cancer. Urology 2005;65:713-8.

28. Molnar B, Ladanyi A, Tanko L, Sréter L, Tulassay Z. Circulating tumor cell clusters in the peripheral blood of colorectal cancer patients. Clin Cancer Res 2001;7:4080-5.

29. Hou JM, Krebs M, Ward T, Morris K, Sloane R, Blackhall F, Dive C. Circulating tumor cells, enumeration and beyond. Cancers (Basel) 2010;2:1236-50.

30. Tanaka F, Yoneda K, Hasegawa S. Circulating tumor cells (CTCs) in lung cancer: current status and future perspectives. Lung Cancer Targets Ther 2010;1:77-84.

31. Cheng M, Liu L, Yang HS, Liu GF. Circulating tumor cellsare associated with bone metastasis of lung cancer. Asian Pac J Cancer Prev 2014;15:6369-74.

32. Hodgkinson CL, Morrow CJ, Li Y, Metcalf RL, Rothwell DG, Trapani F, Polanski R, Burt DJ, Simpson KL, Morris K, Pepper SD, Nonaka D, Greystoke A, Kelly P, Bola B, Krebs MG, Antonello J, Ayub M, Faulkner S, Priest L, Carter L, Tate C, Miller CJ, Blackhall F, Brady G, Dive C. Tumorigenicity and genetic profiling of circulating tumor cells in small-cell lung cancer. Nat Med 2014;20:897-903.

33. Hamilton G, Burghuber O, Zeillinger R. Circulating tumor cells in small cell lung cancer: ex vivo expansion. Lung 2015:193:451-2. 
34. Hamilton G, Rath B, Klameth L, Hochmair MJ. Small cell lung cancer: recruitment of macrophages by circulating tumor cells. Oncoimmunology 2015;5:e1093277.

35. Butler TP, Gullino PM. Quantitation of cell shedding into efferent blood of mammary adenocarcinoma. Cancer Res 1975;35:512-6.

36. Meng S, Tripathy D, Frenkel EP, Shete S, Naftalis EZ, Huth JF, Beitsch PD, Leitch M, Hoover S, Euhus D, Haley B, Morrison L, Fleming TP, Herlyn D, Terstappen LW, Fehm T, Tucker TF, Lane N, Wang J, Uhr JW. Circulating tumor cells in patients with breast cancer dormancy. Clin Cancer Res 2004;10:8152-62.

37. Cohen SJ, Punt CJ, Iannotti N, Saidman BH, Sabbath KD, Gabrail NY, Picus J, Morse MA, Mitchell E, Miller MC, Doyle GV, Tissing H, Terstappen LW, Meropol NJ. Prognostic significance of circulating tumor cells in patients with metastatic colorectal cancer. Ann Oncol 2009;20:1223-9

38. Kahnert K, Kauffmann-Guerrero D, Huber RM. SCLC-state of the art and what does the future have in store? Clin Lung Cancer 2016;17:325-33.

39. Hamilton G, Rath B, Holzer S, Hochmair M. Second-line therapy for small cell lung cancer: exploring the potential role of circulating tumor cell. Transl Lung Cancer Res 2016;5:71-7.

40. Nieto MA, Huang RY, Jackson RA, Thiery JP. EMT: 2016. Cell 2016;166:21-45

41. Tania M, Khan MA, Fu J. Epithelial to mesenchymal transition inducing transcription factors and metastatic cancer. Tumour Biol 2014;35:7335-42.

42. Hamilton G, Hochmair M, Rath B, Klameth L, Zeillinger R. Small cell lung cancer: circulating tumor cells of extended stage patients express a mesenchymal-epithelial transition phenotype. Cell Adh Migr 2016;10:360-7.

43. Diepenbruck M, Christofori G. Epithelial-mesenchymal transition (EMT) and metastasis: yes, no, maybe? Curr Opin Cell Biol 2016;43:7-13.

44. Valastyan S, Weinberg RA. Tumor metastasis: molecular insights and evolving paradigms. Cell 2011;147:275-92.

45. Gunasinghe NP, Wells A, Thompson EW, Hugo HJ. Mesenchymalepithelial transition (MET) as a mechanism for metastatic colonisation in breast cancer. Cancer Metastasis Rev 2012;31:469-78.

46. Khoo BL, Grenci G, Jing T, Lim YB, Lee SC, Thiery JP, Han J, Lim CT. Liquid biopsy and therapeutic response: circulating tumor cell cultures for evaluation of anticancer treatment. Sci Adv 2016;2:e1600274.

47. Weiswald LB, Bellet D, Dangles-Marie V. Spherical cancer models in tumor biology. Neoplasia 2015;17:1-15.

48. Hamilton G, Moser D, Hochmair M. Metastasis: circulating tumor cells in small cell lung cancer. Trends in Cancer 2016;2:159-60.

49. Alvarado-Luna G, Morales-Espinosa D. Treatment for small cell lung cancer, where are we now? - a review. Transl Lung Cancer Res 2016;5:26-38

50. Available at: https://clinicaltrials.gov; search term "SCLC", accessed 09/29/2016.

51. Ruppen J, Wildhaber FD, Strub C, Hall SR, Schmid RA, Geiser T, Guenat OT. Towards personalized medicine: chemosensitivity assays of patient lung cancer cell spheroids in a perfused microfluidic platform. Lab Chip 2015;15:3076-85. 